\title{
Magnitude and Determinants of Opportunistic Infections Among Hiv/Aids Patients in Sphmmc, Addis Ababa, Ethiopia: Retrospective Study
}

\author{
Addisu Deribe* and Wubshet Estifanos \\ Department of Adult Health Nursing Specialty, Ethiopia
}

Submission: August 01, 2018; Published: August 14, 2018

*Corresponding author: Addisu Deribe, Department of Adult Health Nursing Specialty, Ethiopia, Email: wubfiker97@yahoo.com

\begin{abstract}
Background: Opportunistic infections (OIs) are infections that are more frequent or more severe because of immune-suppression in HIVinfected persons, and they are the major clinical manifestation of HIV patients. They indirectly affect the natural history of HIV disease. Severely immune-compromised HIV patients may develop a variety of opportunistic infections that have a significant impact on their well-being, quality of life, health care costs, and their survival. The most common opportunistic diseases in HIV patients are Candida esophagitis, Pneumocystis carinii pneumonia (PCP), disseminated Mycobacterium avium complex (MAC) infection, cytomegalovirus (CMV), Cryptococcus, kaposi sarcoma, herpes zoster, and tuberculosis.
\end{abstract}

Objective: To assess the prevalence and factors associated with opportunistic infections among HIV/AIDS patients in St. Paul's Hospital Millennium Medical College.

Method: A retrospective observational cohort study is conducted on HIV/AIDS patients who started ART clinic in St. Paul's Hospital Millennium Medical College from September 2014 to August 2015. Data is conducted based on a structured and pretested data collection checklist; used to collect demographic, baseline clinical and hematological characteristics and follow up condition of the patients. The data which is completed is fed and analyzed by SPSS 20.0 for windows. Results were reported as tables, pie charts and graphs.

Result: Between September, 2014 to August 2015, 315 patients were started ART follow up, out of these 188 (59.7) are females. The majority of the study patients 122 (38.7\%) were in WHO stage III condition while 91(28.9\%) were in WHO stage IV condition. Of the 315 patients, 149 (47.3\%) had CD4 <200 cells/mm3. From the total patients 264 (83.8\%) developed Opportunistic infections. TB of all forms was 137 (43.49\%), $111(35.2 \%)$ have oral candidacies, 60(19\%) have herpes zoster had the highest prevalence. CD4 count had an independent association with the distribution of the different forms of the opportunistic infections. The Odds of having the severe forms of the opportunistic infections was 6.162 times higher in the patients who had CD4 count less than 200.

Conclusion: TB of all forms, Oral candidacies, and herpes zoster were the predominant OIs. Only

CD count was associated with the distribution of sever forms of the OIs.

Recommendation: Skilled professionals should due attention for age group 20-30, divorced and

CD4 count $<200$ and the implementation of the TB and HIV collaborative activities are of critical importance.

Keywords: HIV Aids Patients; Opportunistic Infections; Art

\section{Introduction}

\section{Background of the Study}

Human immunodeficiency virus type 1 (HIV1 or HIV) has emerged as a major cause of morbidity and mortality in many low and middle income countries around the world. Africa has the highest prevalence of HIV infection and the greatest number of individuals living with HIV. Although Africa accounts for $14 \%$ of the population of the world, $68 \%$ of all HIV-infected individuals live in Sub-Saharan Africa [1]. HIV causes progressive depletion of the CD4 T cells, which leads to life-threatening opportunistic infections (OIs) or malignancies during the natural course of the disease. More than $90 \%$ of opportunistic infections are responsible for the development of AIDS morbidities and mortalities [1,2]. The natural history of HIV disease may be indirectly affected by the occurrence of opportunistic diseases, because HIV viral load increases in patients with acute opportunistic diseases. Survival in people infected with HIV has improved because of an increasingly powerful array of antiretroviral treatments, but neurological symptoms due to co morbidity conditions still remains public health important for HIV infected individuals [1,3]. 
The risk for the development of opportunistic infections in HIV patients depends on exposure to potential pathogens, virulence of the pathogens, the degree of host immunity, and the use of antimicrobial prophylaxis [4]. And majority of these opportunistic infections are associated with an increased hazard of death in HIV patients. Patients experiencing morbidity from opportunistic diseases may have interruptions in antiretroviral therapy causing more rapid progression of HIV disease. In addition studies found that opportunistic infections cause an up regulation in HIV replication and higher viral loads. Severely immune-compromised HIV patients may develop a variety of opportunistic infections that have a significant impact on their well-being, quality of life, health care costs, and their survival. The most common opportunistic diseases in HIV patients are Candida esophagitis, Pneumocystis carinii pneumonia (PCP), disseminated Mycobacterium avium complex (MAC) infection, cytomegalovirus (CMV), Cryptococcus, kaposi sarcoma, herpes zoster, and tuberculosis [5]. Morbidity and mortality in HIV disease result due to underlying immunosuppression which leads to life-threatening opportunistic infections (OIs) during the natural course of the disease [6]. The widespread use of ART starting in the mid-1990s has had the most profound influence on reducing opportunistic infections related mortality in HIVinfected persons in those countries in which these therapies are accessible and affordable. However, opportunistic infections continue to cause morbidity and mortality in HIV/AIDS patients even after ART. Some patients do not have a sustained response to antiretroviral agents for multiple reasons including poor adherence, drug toxicities, drug interactions, or initial acquisition of a drug-resistant strain of HIV-1. Therefore OIs continue to cause substantial morbidity and mortality in patients with HIV1 infection despite use of ART [7,8]. Opportunistic infections are one of the major causes of morbidity and mortality in patients with HIV infection throughout the world. Even if potent combination of antiretroviral therapy (ART) has reduced the incidence of OIs for certain patients with access to care, for those patients in the developed and developing world did not have access to care and have OIs $[7,8]$. The country's response to the HIV epidemic was to establish first a task force in 1985 after the report of the first confirmed case of HIV infections and then a national AIDS council in April 2000. Finally the National council evolved into an office, the HIV/AIDS prevention and control office, HAPCO in 2002 [9].

Since December 2007 HAPCO and its health program department have taken the responsibility to coordinate the health sector response against HIV/AIDS in Ethiopia. The major components of these responses include HIV testing and Counseling (HCT), prevention of mother to child transmission (PMTCT), infection prevention, Anti retroviral therapy (ART), Opportunistic infection Management (IP) [9]. ART was introduced in Ethiopia in 2003 in selected health facilities. The first adult guide line was issued in 2003 [3]. The Ethiopian free ART program was launched in 2005. As of October 2007 the total numbers of patients ever started on treatment were 109,552 out of 187,770 ever enrolled in 272 health facilities including 150 health centers. Nearly all $99 \%$ of the patients are on first line regimen [10].

The statement of the problem Despite the fact that different studies have been conducted on the prevalence of individual opportunistic infections among HIV-infected patients in developing countries like Ethiopia, information about the magnitude and associated factors of opportunistic infections is scarce in the study area. So this study was conducted to assess the prevalence of opportunistic infections and the associated factors for the development of opportunistic infections in HIV Positive Patients taking anti-retroviral therapy (ART) in Saint Paul's Hospital Millennium Medical College.

\section{Objective of the Study}

\section{General Objective}

To assess the prevalence and factors associated with opportunistic infections among HIV/AIDS patients in St. Paul's Hospital Millennium Medical College.

\section{Specific Objectives}

a) To assess the prevalence of the opportunistic infections among HIV/AIDS patients that attend ART clinic of the St. Paul's Hospital Millennium Medical College.

b) To identify factors associated with opportunistic infections among patients in the ART clinic of St. Paul's Hospital Millennium Medical College.

\section{Methodology}

\section{Study Setting}

Saint Paul's millennium medical college is one of the biggest referral hospitals in Ethiopia; located in Gullele, Addis Ababa. St. Paul's Hospital Millennium Medical College as it is known today was established through a decree of the council of ministers of ministers in 2010, although the medical school opened in 2007 and the hospital was established in 1947 by the late Emperor Haile selasie. It is governed under a board federal minister of health. The college initiated Ethiopia's first integrated modular and hybrid problem based curriculum for its undergraduate medical education, and is currently expanding to postgraduate programs and diversifying its undergraduate program offerings. St. Paul's is in the process of building its capacity quickly in short period of time, growing from 3 to 175 faculty members in the last six years, and expanding teaching facilities. It has approximately 1800 clinical and academic, administrative and support staff who provide medical specialty services to patients who are referred from all over the county. While the in patient is 360 beds, St. Paul's sees an average of 700 emergency and out clients daily. The study will be conducted in St. Paul's Hospital Millennium Medical College HIV/AIDS patients who attend ART clinic. 


\section{Study Design}

One year (From September 2014 to August 2015) chart review retrospective study on HIV/AIDS patients who starts follow up at ART clinic in St. Paul's Hospital Millennium Medical College.

\section{Source population}

All adult HIV/AIDS patients who start ART follow up in St. Paul's Hospital Millennium Medical College.

Study population. The clients enrolled in the St. Paul's Hospital Millennium Medical College for chronic HIV/AIDS care and ART follow up were the study population. It was the clinical records of HIV/AIDS enrolled clients who were adults and above 19 years that were included in the study. All people less than 19 years old are excluded.

\section{Inclusion and Exclusion Criteria}

Inclusion Criteria: Clinical records of clients who were adults and 19 years and above were included.

Exclusion Criteria: Clinical records that did not have complete information relevant for the study were excluded.

Sample Size Determination: All patients from September 2014 to August 2015 who started ART clinic follow up and getting the services.

Data Collection Procedure: As chart review retrospective study data was conducted based on a structured and pretested data collection checklist; used to collect demographic, baseline clinical and hematological characteristics and follow up condition of the patients. The data was collected by SPHMMC clinical year students.

\section{Study Variables}

Dependent Variable: Occurrence of sever form of the opportunistic infections.

Independent Variables: Socio-demographic variables (including age, sex, religion, marital status, education level, occupation) and CD4 count.

Data Analysis /Data Quality Management: Collected data were entered and cleaned into a computer and analyzed using SPSS version 23 statistical package. Frequency distribution and percentage calculation was made to describe socio-demographic characteristics and to determine the magnitude of the relative burden of OIS in the ART clinics. Crude and adjusted odds ratio was done to determine whether any association existed with a 95\% confidence interval Binary logistic regression analysis was made to see the relative effect of independent variable (sociodemographic variable) on the dependent variable (severe forms of OIS).

\section{Operational definitions}

Opportunistic Infections: They are a category of infections that occur in immune compromised hosts and considered to be a complication of HIV infection: PCP, CNS toxoplasmosis, TB of all forms.

CD4 count: Their CD4 count and socio-demographic data will be correlated with common opportunistic infections.

\section{Ethical Consideration}

Approval from St. Paul's Hospital Millennium Medical College public health department and academic \& research vice provost was received for this study prior to enrollment. Permission was taken from the responsible body of the unit. Cases were identified by their medical record number not by their names. The information collected was not discussed referring the patient's name. The data is used only for the intended purpose of the study.

\section{Dissemination of results}

After the completion of the study the result will be presented during thesis defenses in the school of public health as a partial fulfillment of my intern-ship. The findings of this study will be circulated to St. Paul's Hospital Millennium Medical College public health department, college's academic and research vice provost and library.

\section{Results}

Table 1: Frequency distribution by major socio-demographic characteristics of HIV/ADIS patients at St. Paul's Hospital Millennium Medical College, Addis Ababa, 2014.

\begin{tabular}{|c|c|c|}
\hline Characteristics & Frequency & Percent \\
\hline Age & & 40.6 \\
\hline $20-30$ & 128 & 26.3 \\
\hline $31-40$ & 104 & 40.3 \\
\hline$>41$ & 83 & 59.7 \\
\hline Sex & 127 & 24.4 \\
\hline Male & 188 & \\
\hline Female & & \\
\hline Sarital status & 77 & \\
\hline
\end{tabular}


Juniper Online Journal of Public Health

\begin{tabular}{|c|c|c|}
\hline Married & 140 & 44.4 \\
\hline Divorced & 68 & 21.6 \\
\hline Widowed & 20 & 6.3 \\
\hline Separated & 10 & 3.2 \\
\hline \multicolumn{3}{|l|}{ Educational status } \\
\hline Not educated & 53 & 16.8 \\
\hline Primary education & 107 & 34 \\
\hline Secondary education & 112 & 35.6 \\
\hline Tertiary education & 43 & 13.7 \\
\hline \multicolumn{3}{|l|}{ Religion } \\
\hline Orthodox & 222 & 70.5 \\
\hline Muslim & 44 & 14 \\
\hline Protestant & 44 & 14 \\
\hline Catholic & 5 & 1.6 \\
\hline \multicolumn{3}{|l|}{ Occupation } \\
\hline Government employee & 82 & 26 \\
\hline Private employee & 70 & 22.2 \\
\hline Daily laborer & 4 & 1.3 \\
\hline House wife & 29 & 9.2 \\
\hline Merchant & 21 & 6.7 \\
\hline unemployed & 109 & 34.6 \\
\hline \multicolumn{3}{|l|}{ Residence } \\
\hline Urban & 257 & 81.6 \\
\hline Rural & 58 & 18.4 \\
\hline
\end{tabular}

Between September, 2014 to August 2015, 315 patients were started ART follow up, out of these 188 (59.7) are females. About $77(24.4 \%)$ of the patients are single, $140(44.4 \%)$ are married and $68(21.6 \%)$ are divorced. Majority, 222(70.5\%) of patients

were orthodox religion followers When classified by occupation majority, $109(34.6 \%)$ of the patients were Unemployed, followed by government employee and $70(22.2 \%)$ are private employee (Table 1) (Figure 1).

\section{\#STAGE I CONDITION $=$ STAGE II CONDITION $=$ STAGE III CONDITION $=$ STAGE IV CONDITION}

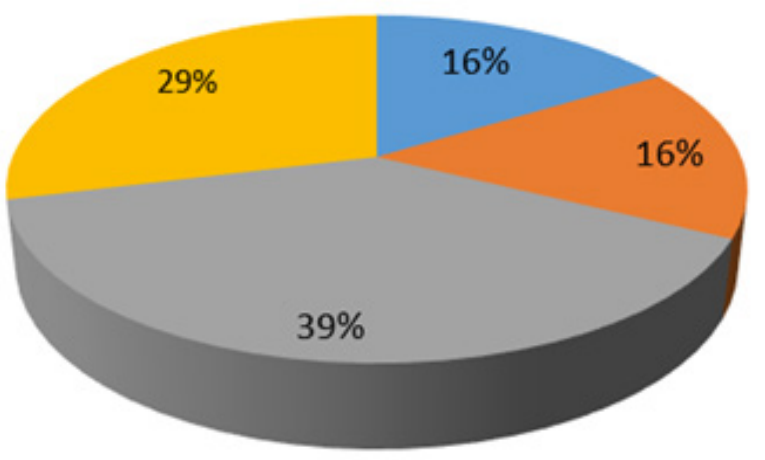

Figure 1: Frequency Distribution of WHO Staging Of HIVIAIDS Patients at St. Paul's Hospital Millennium Medical College, Addis Ababa, 2014.

Of the 315 patients, 166 (52.7\%) had CD4 >200 cells/mm3 and $149(47.3 \%)$ had CD $<200$ cells/mm3. From the total patients $264(83.8 \%)$ developed Opportunistic infections (Table 2).

\section{The Types and Frequencies of the Opportunistic Infections}

Out of the 315 clinical records assessed in 2014 for the presence of the OIs, 111(35.2\%) had oral candidiasis, 78(24.8\%) 
had pulmonary TB, 60(19\%) had herpes zoster, 59(18.7\%) had Extra pulmonary TB and $38(12.1 \%)$ have recurrent bacterial pneumonia were found out to be the predominant OIs observed in the order given. When the frequencies for both pulmonary and extra pulmonary TB were combined the prevalence for TB of all forms was 137 (43.49\%) making it the most predominant OI in the study subjects (Table 3 ).

Table 2: Frequency distribution of CD4 count of ART patients in St. Paul's Hospital Millennium Medical College in 2014.

\begin{tabular}{|c|c|c|}
\hline Patient CD4 Count & Frequency & Percent \\
\hline CD4 count $<200$ & 149 & 47.3 \\
\hline CD4 count $>200$ & 166 & 52.7 \\
\hline Total & 315 & 100 \\
\hline
\end{tabular}

Table 3: Types and frequencies of opportunistic infections in St. Paul's Hospital Millennium Medical College, Addis Ababa, 2014.

\begin{tabular}{|c|c|c|}
\hline Opportunistic Infection & Frequency & Percent \\
\hline Oral Candidiasis & 111 & 35.2 \\
\hline Esophageal Candidiasis & 19 & 6 \\
\hline Herpes Zoster & 60 & 19 \\
\hline Recurrent Bacterial Pneumonia & 38 & 12.1 \\
\hline Pulmonary TB & 78 & 24.8 \\
\hline Extra Pulmonary TB & 59 & 18.7 \\
\hline
\end{tabular}

\begin{tabular}{|c|c|c|}
\hline Mycosis & 11 & 3.5 \\
\hline Pneumocystis carnii Pneumonia & 21 & 6.7 \\
\hline Cryptosporidial diarrhea & 11 & 3.5 \\
\hline CNS toxoplasmosis & 9 & 2.9 \\
\hline Cryptococcal meningitis & 7 & 2.2 \\
\hline Primary CNS lymphoma & 2 & 0.6 \\
\hline
\end{tabular}

Socio-Demographic Characteristics and the Occurrence of the Opportunistic Infections

A Multivariate logistic regression model was used to see the association between the occurrence of the opportunistic infection with socio-demographic variables, the CD4 count of the patients. The CD4 count of the clients of at this Hospital was associated with the distribution of the occurrence of OIs among the study population. Age group 31-40 and being divorced had independent association for the distribution of the different forms OIs. This age group has 18 times preventive value compared to other age groups. Being divorced has 7.1 times higher risk of developing OIs in study subjects. The CD4 count had an independent association with the distribution of the OIs. The Odds of having the severe forms of the OIs was 6.162 times higher in the patients who had CD4 count less than 200 (Table 4).

Table 4: Multivariate logistic regression showing factors associated with Opportunistic infections in HIV/AIDS/ ART clinic, St. Paul's Hospital Millennium Medical College, Addis Ababa, 2014.

\begin{tabular}{|c|c|c|c|c|}
\hline \multirow{3}{*}{ Variables } & \multicolumn{2}{|c|}{ Opportunistic Infection } & \multirow{3}{*}{ OR $(95 \% \mathrm{CI})$} & \multirow{3}{*}{ p-Value } \\
\hline & \multirow{2}{*}{$\begin{array}{c}\text { Yes } \\
\mathrm{N}\end{array}$} & \multirow{2}{*}{$\begin{array}{c}\text { No } \\
\text { N }\end{array}$} & & \\
\hline & & & & \\
\hline \multicolumn{5}{|l|}{ Age (years) } \\
\hline $20-3$ o & 95 & 33 & 1 & \\
\hline $31-40$ & 91 & 13 & $0.185(0.069,0.495)$ & $0.001^{*}$ \\
\hline$>41$ & 78 & 5 & $0.449(0.153,1.315)$ & 0.144 \\
\hline \multicolumn{5}{|l|}{ Sex } \\
\hline Male & 112 & 15 & 1 & 0 \\
\hline Female & 152 & 36 & $1.768(0.923,3.387)$ & 0.086 \\
\hline \multicolumn{5}{|l|}{ Marital status } \\
\hline Single & 58 & 19 & 1 & \\
\hline Married & 117 & 23 & $1.666(0.841,3.303)$ & 0.144 \\
\hline Divorced & 65 & 3 & $7.098(1.997,25.225)$ & $0.002^{*}$ \\
\hline Widowed & 14 & 6 & $0.764(0.258,2.268)$ & 0.628 \\
\hline Separated & 10 & 0 & $99(0.00)$, & 0.999 \\
\hline \multicolumn{5}{|l|}{ Educational level } \\
\hline Not educated & 45 & 8 & 1 & \\
\hline Primary & 92 & 15 & $1.090(0.431,2.761)$ & 0.855 \\
\hline Secondary & 94 & 18 & $0.928(0.375,2.296)$ & 0.872 \\
\hline Tertiary & 33 & 10 & $0.587(0.209,1.647)$ & 0.311 \\
\hline \multicolumn{5}{|l|}{ Occupation } \\
\hline Government employee & 68 & 14 & $1.025(0.480,2.190)$ & 0.948 \\
\hline Private employee & 58 & 12 & $1.020(0.461,2.258)$ & 0.96 \\
\hline
\end{tabular}




\section{Juniper Online Journal of Public Health}

\begin{tabular}{|c|c|c|c|c|}
\hline Daily laborer & 2 & 2 & $0.211(0.028,1.594)$ & 0.132 \\
\hline House wife & 27 & 2 & $2.850(0.624,13.020)$ & 0.177 \\
\hline Factory worker & 19 & 2 & $2.006(0.430,9.343)$ & 0.375 \\
\hline Unemployed & 90 & 19 & 1 & 0.81 \\
\hline Residence & & & & \\
\hline Urban & 216 & 41 & $1.098(0.514,2.344)$ & \\
\hline Rural & 48 & & 1 & $0.001 *$ \\
\hline CD4 count & 141 & 8 & $6.162(2.790,13.610)$ & \\
\hline$<200$ & 123 & 43 & 1 & \\
\hline$>200$ & & & & \\
\hline
\end{tabular}

\section{Discussion}

Determining the types and relative frequencies of the major OIs and possible determinant factors is important for proper management and prevention strategy of the common OIs. The overall OI prevalence at intake and follow up in St. Paul's Hospital Millennium Medical College ART clinics is high. The types of the OIs were various ranging from the common oral candidacies to the life threatening CNS toxoplasmosis and the fungal cryptococcal meningitis. The results of this study compared more or less in a similar manner to studies done in Ethiopia previously and other countries. This study indicated that, the overall incidence rate of OIs in patients, 111 (35.2\%) have oral candidiasis, 78 (24.8\%) have pulmonary TB, 60 (19\%) have herpes zoster, 59 (18.7\%) have Extra pulmonary TB and $38(12.1 \%)$ have recurrent bacterial pneumonia were found out to be the predominant OIs observed in the order given. In contrast to the studies that we have mentioned above and to this study as well a prospective study on the development of OIs in HIV infected patients in the USA showed PCP as the predominant OI [11] followed by esophageal candidiasis, mycobacterium avium complex, CMV retinitis, Bacterial pneumonia, cryptococcosis and TB [11]. In the USA study there was a difference in the prevalence by sex and HIV exposure mode. Esophageal candidiasis, tuberculosis, herpes simplex were significantly higher among women. Kaposis sarcoma was frequent among men. A cross-sectional study conducted among 100 HIV positive patients in Phenome, Cambodia at 2 general hospitals revealed the following findings [6]. Oral candidiasis $80 \%$, esophageal candidacies (39\%), pulmonary TB 25\%, extra - pulmonary TB $28 \%$, cryptosporidiosis $13 \%$, and PCP $10 \%$. No statistical significant difference was found between gender, age, occupation or residence in the Cambodian study. The findings from this study were similar to the Cambodian one except that herpes zoster was not present in the Cambodian case.

On the other hand a screening test for the presence of opportunistic infections on 80 confirmed HIV positive patients in a tertiary care hospital in New Delhi, India showed [7], pulmonary Tuberculosis in $31 \%$ of cases, chronic diarrhea in $12 \%$ of cases, oral candidiasis in $7 \%$ of cases, herpes zoster in $7 \%$ of cases, cryptococcal meningitis in $2.5 \%$ of cases, PCP in $1.5 \%$ of cases and CNS toxoplasmosis in $1.5 \%$ of cases [8]. The current study has a similar pattern in the presentation of the OIs.
A one year prospective study of consecutive patients admitted to the medical wards of Tikur Anbassa hospital had shown the morbidity and mortality patterns of patients with HIV/AIDS and the common OIs observed were, oropharyngeal candidiasis $57.4 \%$, tuberculosis $55.6 \%$, sepsis $24.9 \%$, herpes zoster $16.9 \%$ and cryptoccocal meningitis 5.9\%. A different study that was done at Zewiditu Memorial hospital in 2005 on 186 HIV/AIDS patients to determine the proportion of patients who developed the immune reconstitution inflammatory syndrome (IRIS) found out that prior to the start of HAA RT the patients had the following OIS [9]. Herpes zoster was present in $43 \%$ of the cases; tuberculosis in $31.4 \%$ of the cases; Oral candidacies in $16.4 \%$ of the case, toxoplasmosis of the CNS in $2.3 \%$ of the cases and PCP in $2.1 \%$ of the cases. The relative distribution of the OIs in the present study is similar to the two studies below except the slight difference in the order of the OIs.

A prospective study at Tikur Anbasa Teaching Hospital on 100 HIV positive patients in 1999 and the demographic, social and clinical presentations were reviewed. Pulmonary tuberculosis was present in $26(26 \%)$ of cases and extra pulmonary TB in $29 \%$ of the cases. A retrospective clinical record analysis was done at the Ministry of health from 2004GC. The study was a nationwide review of 636 HIV/AIDS cases and the findings were, tuberculosis in 239 (25\%) of cases; Herpes zoster in 203 (21.6\%) of cases and oral candidacies in $200(21.6 \%)$ of cases and PCP in $6(0.6 \%)$ of cases. A retrospective cross-sectional study was done in Jimma referral hospital, south west Ethiopia on 925 HIV/AIDS patients from July 1993-June 1997. The patients were in the hospitals AIDS control program and review of the clinical profiles of the patients were; tuberculosis 239 (25\%). herpes zoster 203 (21.9\%), oropharyngeal candidiasis 200 (21.6\%), herpes simplex 16(1.7\%) and PCP $6(0.6 \%)$.

In the above 3 studies TB both pulmonary and extrapulmonary, herpes zoster and oral candidiasis were the main presentations in the HIV/AIDS patients. In the present study also TB of all forms was $45 \%$ of the total cases and is first in rank and followed by oral candidacies which are similar to the above studies. This study indicated that, When the frequencies for both pulmonary and extra pulmonary TB were combined the prevalence for TB of all forms was 137 (43.49\%) making it the most predominant $\mathrm{OI}$ in the study subjects. The finding in this study is consistent with the above studies done in 
Ethiopia. The distribution of the occurrence of OIs was similar in all sociodemographic data except the age. Risk factor found to be associated in this study was advanced clinical stage of HIV disease and CD4 level below 200. In a study to assess central nervous system opportunistic infections a retrospective study was done on the clinical records of 126 HIV infected patients in a Thailand outpatient and inpatient university hospital. Cryptococcal meningitis was present in $94(75 \%)$ of the patients followed by tuberculosis meningitis $9(7 \%)$. The explanation given of the high prevalence of cryptococcal meningitis by the authors was that cryptococcal meningitis was highly endemic in Thailand even prior to the HIV epidemic. Another study done in New York City on the prevalence cryptococcal meningitis found where the annual prevalence of the disease rose to $6 \%-8.5 \%$ from a low prevalence rate of 1 case per million prior to the AIDS epidemic [11].

A study done in Tikur Anbesa hospital Addis Ababa, Ethiopia to find out the occurrence of cryptococcal meningistis in HIV patients over a 2 year period from October 1998-April 2000 showed the following. Out of 1088 cerebrospinalfluid / CSF/ lab investigations the disease was found in $19(7 \%)$ of the cases. The findings of cryptococcal meningitis in this study were $21(2.2 \%)$ which is lower than the above findings [12]. In summary the types and frequencies of the different OIs in this study were similar to the various studies done previously in this country and many studies done in Brazil, Cambodia, India and Thailand. Oral candidiasis $(35.2 \%)$ is the leading OI in the study and when pulmonary TB $(24.8 \%)$ and extra pulmonary TB (18.7\%) are combined together TB of all forms comprises of 137 (43.49\%) making it the most predominant OI in the study subjects, which is the second most prevalent OIs in other studies [13]. Herpes zoster is third in rank of presentation $60(19 \%)$ in the list. Other finding in this study is the occurrence of primary CNS Lymphoma with the prevalence of $2(0.6)$ in contrast to other studies done in Ethiopia were not documentation [14]. Low incidence rate cryptosporidiosis with diarrhea observed in present study compared to other studies done in Ethiopia and abroad countries. The rate of PCP is higher compared to the result from other Ethiopia and New Delhi but lower compared with finding from study done Brazilian university hospital and USA [15]. The CD4 count had an independent association for the distribution of the different forms OIs. The odd's of having the different forms of the OIs was 6.16 times higher in the study subjects who CD4 count less than 200. In contrast to other studies, the age group 31-40 and being divorced had independent association for the distribution of the different forms of OIs but there is no statistically significant difference in the distribution of the OIS with sex, religion, education level or occupation. Being divorced has 7.1 times higher risk of developing OIs in study subjects.

\section{Limitations of the Study}

a) The study was done on a secondary data which makes the result obtained less informative than that done using a primary data using a prospective study. b) A prospective study was not done because prospective studies take very long time, costly and need more resources.

c) Some of the studies that were reviewed for comparisons were prospective studies. The other studies were screening studies. Some others were retrospective clinical record reviews which makes direct comparison with the current study difficult.

\section{Conclusion and Recommendation}

\section{Conclusion}

Out of the clinical records assessed for the presence of OIs, TB of all forms 137 (43.49\%), Oral candidiasis 111(35.2\%), and herpes zoster $59(18.7 \%)$ were found out to be the predominant OIs observed. Age group 20-30 and $>41$ and being divorced had independent association for the distribution of the different forms OIs. Being divorced has 7.1 times higher risk of developing OIs in study subjects. The CD4 count had an independent association for the distribution of the different forms OIs. The odds of having the different forms of the OIs was 6.16 times higher in the study subjects who CD4 count less than 200 [16].

\section{Recommendation}

The ART clinic skilled health professionals need to have give attention to age group 20-30 and >41, divorced and those who had CD4 count less than 200 for proper diagnosis and management of the prevalent OIs in the population. Documentation and determination of the viral load had important factor for knowing further distribution of OIs. Encouraging documentation of viral load has vital role [17]. TB of all forms has high contribution to the disease burden and it is the leading OI presenting in $45 \%$ the cases. Strengthening of the implementation of the TB/HIV collaboration activity is of vital importance.

\section{Refernces}

1. Gordon C Cook, Alimudin I Zumla Manuals of Tropical disease $\left(22^{\text {nd }}\right.$ edn.); pp. 373-390.

2. Facuci Baunwald (2007) Harrison's principle of Internal medicine (17 ${ }^{\text {th }}$ edn.); $1: 1169-1200$.

3. WHO, AIDS Epidemic update December.

4. BN Konjo, JL HARWEL (2007) opportunistic infections and HIV clinical diseases among patients in PHONOM PENH, Cambodia, South West Asian. Journal of Tropical medicine and public health 38(1): 62-68.

5. Goodgame RW (1996) Understanding intestinal spore forming protozoa: Cryptosporidia, Microsporidia, Isospora and Cyclospora. Ann Intern Med 124(4): 429-441.

6. Fmoh Hapco (2007) monthly HIV care and ART update.

7. Dawit Woilday, Tsehaynesh Messele (2003) Prevalent infectious diseases in patients with HIV/AIDS in Ethiopia, Ethiopian medical Journal 43(2): 189-197.

8. Hailu Negass, Hailu Kefene (1990) Profile of AIDS case in Ethiopia. Ethipian Journal of health development 4(2): 213-217.

9. Lissane Seifu (2004) Socio-demographic and clinical profiles of AIDS patients in Jimma referral hospital, south west Ethiopia EPHA 18(3): 131-212.

10. Woldeamanuel Y, Haile T (2001) cryptococcosis in Patients from Tikur 


\section{Juniper Online Journal of Public Health}

Anbasa Hospital, ADDIS ABABA, ETHIOPIA. Ethiopian medical Journal 39(3): 185-192.

11. NIMFA M Putong (2002) Mycobacterium tuberculosis among HIV/ AIDS patients in Thailand, South East Asian Journal of Tropical medicine and public health 33(2): 346-350.

12. Walker AS (2010) Prophylaxis treatment in Immuno suppressed HIV adult patients in Africa who started on ARV therapy; an observational analysis of DART Cohrt. The Lancet 375(9722): 1278-1286.
13. Assefa Yared Mekonen, country analysis of family planning and HIV/ AIDS/STI in Ethiopia, Addis Ababa.

14. Agarwl SK, Makhija A (2002) International Conference on AIDS.

15. Jonatan E Kaplan, Henry Masur (2000) Prevention of OIS in persons infected with HIV; Clinical infection diseases 30: s1-4.

16. Agarwl SK, Makhija A (2002) International Conference on AIDS.

17. HAPCO (2007) National comprehensive HIV/AIDS Chronic care-ART Training manual.

This work is licensed under Creative

Commons Attribution 4.0 License

DOI: 10.19080/JOJPH.2018.04.555627 